\title{
Linguistic Taboos: A Case Study on Australian Lebanese Speakers
}

\author{
Fouad Abi-Esber ${ }^{1}$, Ping Yang ${ }^{2}$, Hiromi Muranaka² \& Mohamed Moustakim ${ }^{2}$ \\ ${ }^{1}$ Western Sydney University, Sydney, Australia \\ ${ }^{2}$ School of humanities and communication Arts, Western Sydney University, Sydney Australia \\ Correspondent: Ping Yang, School of humanities and communication Arts, Western Sydney University, Sydney \\ Australia. E-mail: p.yang@westernsydney.edu.au \\ Fouad Abi-Esber, Western Sydney University, Sydney, Australia. E-mail: fouadabiesber@hotmail.com
}

Received: September 26, 2017

Accepted: October 16, $2018 \quad$ Online Published: February 28, 2018

doi:10.5539/ach.v10n1p89

URL: http://dx.doi.org/10.5539/ach.v10n1p89

\begin{abstract}
This study aims to investigate how Lebanese Arabic speakers living in Australia utilise their linguistic taboos, with the purpose of comprehending their cross-cultural adaptation in the Australian context. The specific research focal point of this study includes how and why Lebanese Arabic speakers of different age range use linguistic taboo words. A total of 56 Lebanese students were deemed to satisfy the participation criteria. A research tool, NVIVO 10 software, was used to analyse the questionnaires and interviews and to help sort major themes, as identified above, for critical discussion. The results show that the older participants tend to use a specially designed euphemistic form of linguistic taboo whereas the younger participants' use of linguistic taboo is much influenced by some factors such as peer pressures and video games, and they do not always use more taboo words than older participants as reported in previous research. The results indicate the complicated and dynamic sociolinguistic context of the Lebanese community regarding the use of linguistic taboo in Australia. Additionally, it provides insights into how Lebanese speakers manage linguistic taboos successfully in social interactions using their cross-linguistic skills and cross-cultural knowledge.
\end{abstract}

Keywords: linguistic taboos, Australian Lebanese, euphemism, older and younger participants

\section{Introduction}

In the field socio-linguistics, many researchers have studied linguistic taboo (LT) (Al-Khatib, 1995; Qanbar, 2011), and one of contentiously debatable topics is the relationship between the generational differences and the use of taboo words. Some studies have investigated the use of LT by young Arabic speakers (Abdel-Jawad, 2000; Al-Azzeh, 2010; Al-Khatib, 1995), most of which have concluded that older speakers tend to use euphemistic expressions in their communication with others, while younger male speakers tend to frequently use swear words in their conversations. However, Arabic is spoken in many countries including parts of Africa and the Middle East, and there are some cultural differences in relation to religion, and other co-existing languages. As far as Lebanon is concerned, there is little to no research, which specifically addresses the perception and attitudes of Lebanese speakers either in Lebanon or across the diaspora about the generational differences and the use of taboo words.

As there is no specifically focused research conducted on the use of taboo words in the Lebanese community in the Australian context, where English is the majority language outside the community, Arabic researchers are yet to conduct research, which could confirm or contradict the general perception that younger generation speakers are more liable to use obscene or profane words than their older counterparts.

\section{Literature Review}

\subsection{Definition of Taboo}

The definition of taboo varies depending on authors and academics. For the majority of people, the meaning of the word, 'taboo' remains obscure. This confusion is most evident in one of the branches of the LT that embrace swearing. Jay (2009) notes that there is a misperception in psychological science and in society at large concerned with how regularly people embark on swearing and what it means when they do. It is important to consult the literature on the existing definition of taboo. 
The word, 'taboo' is borrowed from the Tongan tapu, an adjective that refers to persons or objects under prohibition (Burridge, 2010; Chu, 2009). The adoption by the English language of this foreign word with the variation of spelling, caused the loss of its spiritual meaning. The word still implies that a person is prohibited from doing certain things and that objects can also be under prohibition. Fershtman, Gneezy and Hoffman (2011) contemplate a taboo as an 'unthinkable' action and the thought of breaching one can prompt social punishment. They consider that taboos are the social 'thought police', discouraging individuals from considering a specific type of action. This definition of taboos seems to be logical.

Taboos act as mechanism to restrain people from breaking rules. However, it is not a law in itself as there is a distinction between the meaning of law and taboo. Law is a legal system of social rules that regulates the conduct of members of societies and is derived from human practices (Hart, 1977). Similarly, Fitzpatrick (1992) expresses that law is explained by the functions it performs and this is seen as a straight forward relation of effectiveness in its impact on behaviour or in social change, while taboo is conceived as part of community social norms. In the Arabic culture, it is inappropriate to mention the word 'God' unnecessarily in a non-religious context. Moreover, it is also improper to degrade God or link Him with obscene or offensive words No doubt, the West also has ritual or religious restrictions despite the spread of liberalism. According to Asad (2008), secularists see blasphemy as a restriction on the freedom of speech that is guaranteed by the Western principles. Furthermore, he continues that blasphemy has a long history in Christianity which is considered to be an insult to God's honor and it is therefore a sin in its course. In Arabic culture, it is not proper to degrade God, while in the West, blasphemy is not tolerated any more than in the East.

\subsection{Different Attitudes Towards Taboos}

There are different attitudes towards taboos and they vary from region to region and from culture to culture. While some people try to reinforce them, others do not enforce them in their societies because what is considered as taboos_in one region_is not necessarily so in another region. Fleming and Lempert (2011) remark that efforts to outlaw speech may be justified differently by appeals to etiquette, state policy, and religious dictates. The reason for proscribing speech can be justified, where society attempts to see its citizens adhere to the basic rules of decency. Chu (2009) points out that each culture has its own taboos. They are culturally oriented and socio-contextually interpreted, according to the values of a particular society's beliefs, norms, perceptions and attitudes (Agyekum, 2002; Gobert, 2015). The cultural orientation of taboos illustrates how countries are different in their perception and adaptation of taboos in their lives. Therefore, Lebanon and Australia might not share exactly the same taboos. Gobert (2015) perceives that taboos may be openly discussed or performed in one culture (e.g., same-sex marriage, sex topics, and abortion) yet may be highly tabooed in another culture. Most Lebanese speakers avoid using words or expressions that are considered taboo in content. The most unmentionable type of taboo words for Lebanese speakers include heavily toned Arabic swear words that refer to private parts or negatively target the mother or sister of the listener. Ziman (2008) observes that taboos do not need external assistance to maintain their power over members of a culture. People will try to keep away from tabooed objects or to avoid certain things considered taboo whenever possible out of fear. Following an in-depth perusal of the existing literature about taboos, it may be possible to categorise the types of taboo as follows: sex taboos, racial taboos, cultural taboos, religious taboos, social taboos and LT.

\subsection{Taboo Management}

In order to avoid LT, speakers have to use linguistic techniques and rhetorical devices to manage it. Qanbar (2011) remarks how the Yemenis employ a number of strategies to avoid uttering taboo words. These strategies include euphemism, creating antonyms, metaphoric expressions, antonyms and jargon. In order to manage LT, speakers might code switch from L1 to L2 or resort to euphemism. The participants in Eilola and Havelka's (2011) research feel nothing when uttering or hearing L2 taboo words. Therefore, L2 seems to be associated with less intense emotional arousal in some bilingual speakers' cases.

\subsection{Euphemism}

As stated in the above section, one of the most common taboo management strategies is euphemism. Halmari (2011) notes that humans have always resorted to euphemisms: vague and indirect expressions in their bid to escape life's tough realities and that in euphemistic use of language, one expression is replaced by another. Burridge (2010) observes that taboo words are avoided so as not to offend the audience. Speakers attempt to utter words that do not necessarily offend others. The choice of words is regarded as a must by many. In the Arab world and in Lebanon, offending the listener is not tolerated under any circumstances. It is the responsibility of the speaker to ensure that they are polite at all times in order to be accepted by the listener, and euphemism may be used to avoid offensive words. Duda (2011) notes that straightforward remarks may at times be regarded as 
offensive and therefore, speakers have no choice but to avoid using strong LTs. The anticipation of a reaction by listeners may be one of the reasons speakers try to avoid making straightforward remarks. Farghal (1995) expresses that euphemistic expression manifests in the conscious selection of a more polite lexis instead of a less polite one. The selection of less polite words in the Arabic language is possible due to the fact that the Arabic language contains a large repertoire of words. It is a similar situation in other Arab countries, for example, Jordan. Luffin (2002) states that a taboo word may be replaced with either a synonym or a periphrasis that is either its opposite or has another meaning but is phonetically very close. It seems that speakers may resort to different management strategies as they see fit to their situations.

\subsection{Linguistic Taboos (LT) and Generational Differences}

LT is a universal notion practised by every society in the world (Agyekum, 2002). It is worth observing that LT goes alongside morality and compels people to comply with acceptable norms and behaviours in society. Burridge (2010) notes that LT directly serves human interests by setting apart those things that threaten to cause anguish and distress. Hence, speakers are aware of the implications of LT and the need to ensure that their speeches are free of it. Maqdum (2011) mentions that the Arabic language is distinguished from other languages due to its diversity of styles. He continues that among the styles that characterise the Arabic language is the same gentle and polite approach also found in the English language. Therefore, participants are expected to choose words that are courteous and respectful and that adhere to the Arabic speaking standard. Maqdum (2011) observes that Arabic people try to avoid some words in order to ward off harm. The avoidance of words is a way to ensure that speakers do not appear impolite to listeners.

Adolescents and older people may not share the same speech characteristics, according to previous research. De Klerk (1992) has conducted a study, which revealed that the more dominant the adolescents, the more likely they adopt anti-social linguistic messages of high intensity. De Klerk (1992) asserts that people in their adolescence test authority and the strength of taboos in direct proportion to the amount of social power they appear to have. Klerk's findings confirm the public notion that some younger speakers are more likely to use taboo words than the older ones.

Sabri (2012) also has shown in his research that the participants' age has a compelling influence on his or her evaluation of the extent of taboo violation. Holmes (1992) states that it is assumed that teenagers use more taboos than adults or children. Older people may use euphemistic expressions possibly because they pay more attention to their behaviour and care more about their self-image in the eyes of the younger generation (Al-Azzeh, 2010). Any investigation into how age impacts speakers' perceptions of LT is a step forward at a time when the world is in constant evolution. Generally, older Lebanese speakers ensure they set a good example for the younger generation.

It is important to understand the factors that compel young speakers to use LT words. Stenström (2006) and Barbieri (2008) remark that teenagers' talk also features new slangs that contains taboo words. Barbieri (2008) mentions that little is known about how much a speaker's language varies across their lifespan. According to Barbieri (2008), older people do not use slangs or swear words (similar to younger ones) where they opt to favour modals. Thanjitt (1998) states that the perception of taboos between younger and older people differs significantly. He adds that youngsters use the terms not only to express anger, insults and disappointment but also to joke and show joy (Thanjitt, 1998). Taboo words seem to reflect positive intentions beside negative ones, and these young speakers might find them appropriate in their communication, especially among their friends and peers with whom they might joke. Thanjittt (1998) notes that older people understand how to behave and control themselves more than young people and that because they are adults, they are more aware of their behaviour and societal conventions. Thanjitt (1998) further remarks that many old people use taboo words as a means for showing familiarity or affection to younger people. He adds that the younger generation uses taboo terms more often than adults and that all age groups of both sexes perceive the names of certain parts of the body as taboo terms, which must not be taken lightly, and which have the most impact in utterance (Barbieri, 2008; Thanjitt, 1998). Surprisingly, Blamire, Laturnus and Perez-Leon (2013) do not see that younger people use improper and profane words.

The use of strong LTs may not be exclusive anymore to young people and some older people see no harm in using such words. Stenstrom (2006) observes that young people's language has not attracted as much attention in academic circles as child and adult language has and this may be due to the lack of recorded data in the form of corpora that are accessible for research. Extensive research on the language of youth is essential in order to make comparison between the use of strong LTs among young and old speakers. In his study, Stenstrom (2006) shows that the majority of taboo words used both in English and Spanish girls' conversations are related to sex. This 
finding may again demonstrate how young people are likely to use strong LTs. The English word 'fuck' is so constantly and colourfully used in the English world that Johnson (1995) wrote a book about how it is used for effective everyday communication. Murphy (2009) also observes in the data gathering that this F word was the most commonly used by male participants in their twenties. At the time of the study, this word appeared as a leading, strong LT, however, it would be worth investigating if this remains the case nowadays. Thelwall (2008) acknowledges that swearing occurs across all ages but the swearing rate peaks in the teenage years and declines thereafter. His observation was supported by research he conducted showing that the social network website, MySpace (with users up to age 40) - where the average age of users is 16-years-old with $15 \%$ of users in their middle age - contains strong swearing. This finding reinforces the common perception that older speakers use weaker LT taboo words than younger ones.

Thelwall (2008) remarks that swearing has been shown to decline with age and that there is sufficient data garnered again from MySpace to support this theory. Unfortunately, there is no similar study conducted in Australia that shows the trend of young Australian's usage. As far as the issue of swearing is concerned, Ritt-Benmimoun and Procházka (2011) note that as in other semantic fields, the choice of words in the Arabic world depends on the age and education of the speaker. Abdel-Jawad (2000) also claims that conversational swearing is more commonplace and elaborate among younger male speakers, as well as among less educated and lower class people. Moreover, it is important not to ignore the fact that the perception of LT can depend largely on interpersonal characteristics and attitudes of the individual. For example, a polite person, regardless of his or her age, may refrain from using LT due to their belief that uttering such words is unethical and inappropriate. These claims need to be investigated by other researchers, as it will be hard to presume its validity without further confirmation.

\section{Methodology}

\subsection{Research Design}

The generational difference in the use of LT among Australian Lebanese speakers will be focused in this study, and it will answer the following research question: What is the impact of age on the usage of LT?

This study employed data collection techniques, including questionnaire and open-ended ethnographic interviews. A descriptive questionnaire focused on exploring the attitudes of Lebanese speakers in Australia regarding Arabic taboos, with a mixture of closed-ended multiple-choice and open-ended questions was used. The closed-ended questions used semantic differential scales and Likert scales. The use of varying scales aimed to illuminate how participants distinguished categories and chose their preferred expressions from a range of verbal statements (Dawes, 2008). In the open-ended questions, participants were invited to provide qualitative responses/answers. The data and qualitative comments from participants thus aims to provide valuable insights to inform the analysis.

In the second part of the questionnaire, participants were asked to respond to different scenarios where the Discourse Completion Test (DCT) (Zuskin, 1993) was used. DCT is designed to "elicit responses to problematic, contextually-specific prompts" (Zuskin, 1993, p. 174) as participants provide their answers. These techniques not only simulate real life communication but also provide meaningful context where interaction with interlocutors produces successful outcomes. Originally, the intention was to record interviews, however, the objection of the majority of participants meant that the research relied on written discourse completion of different situations. The objection was based on the fear of the identification of themselves if these recorded excerpts were used later by the researcher in future conferences or seminars.

It is hoped that the research is able to show what participants do and do not share as far as the usage or non-usage of taboos. Moreover, the qualitative comparison in this research identifies whether old and young participants display different perceptions of LT. Once the data was collected, questions were asked about the implications of the results and the goal to answer the research question.

\subsection{Participants}

To participate in the questionnaire, participants needed to meet the following criteria:

- To be of Lebanese descent, as the research focuses on Australians of Lebanese background and also Lebanese immigrants who have made Australia their home.

- To be aged between 18 and 60. This age range was used in order to attract participants of various age groups. Anyone not in this age range was not considered for selection to participate in this research owing to the fact that participants needed to have reached the legal age (i.e. 18) in order to be interviewed. 
Furthermore, many older participants were not willing to be involved with the research due to illness or other personal reasons.

- To meet the quota of 60 participants, half Muslims and half Christians, and half male and half female, were intended to ensure that results are non-biased toward a particular religious or gender group. However, more Christian than Muslim participants took part in the research. The reason could be owing to the fact that Muslim participants were too shy to discuss their LTs.

- To have resided in Australia for at least six months prior to participation. In this research, the participants needed to have resided long enough in Australia in order for them to be part of the Australian Lebanese community.

- Sixty people were approached to participate in this research. However, a total of 56 Lebanese students were deemed to satisfy the participation criteria. Each of the participants was coded between 1 to 56 for identification purposes, and in the analyses, their group code was added, for example, OP for older participants and YP for younger participants. The background information of the recruited participants is presented in Table 1.

Table 1. Participants' background information

\begin{tabular}{lcccc}
\hline & Number of Participants (\%) & Male & Female & Age Range (years) \\
\hline Older Participants & $14(25 \%)$ & 3 & 11 & $30-60$ \\
Younger Participants & $42(75 \%)$ & 18 & 24 & $18-29$ \\
\hline Total & $56(100 \%)$ & 21 & 35 & \\
\hline
\end{tabular}

The researcher's rationale for age brackets for the participants' design is based on the fact that older participants were unlikely to have attained sufficient academic qualifications due to their experience of war in Lebanon while the younger participants were more likely to have attained some sort of academic qualifications and more likely to have exposed to the use of strong LT.

\subsection{Data Collection}

The data collection comprised of two phases: the online questionnaire and the interview section, which had two parts. The researcher liaised with the male participants while the female research assistant liaised with female participants due to cultural reasons. In order to achieve a good response rate from both data collection methods, the researcher has used an accurate population list/sampling frame. It was ensured that the questions used in both methods, identified better response rates from the respondents (Denscombe, 2014).

\subsubsection{Questionnaire}

The questionnaire asked the participants to select the preferred definitions of LT and the various types of taboos, particularly in relation to how age influenced speakers' attitudes toward the use of LT during their social interactions. Most of the participants completed the questionnaire online through a survey questionnaire, this allowed participants to consult with one another. The research used scale labels, as adopted by Sue and Ritter (2007). However, the order was reversed to start the question with 'strongly agree' instead of 'strongly disagree'.

\subsubsection{Interview}

Of the 56 participants in the questionnaire study, 22 were interviewed. It was ensured that one half of the participants were Muslim and the other half of them Christian and with an even split of females. The selection criteria were based on the fact that these participants have demonstrated their motivation in the completion of the questionnaire. In this research, interviews aimed to show the thoughts and experiences of participants regarding LT. Face-to-face interviews allow the interviewer to build a rapport with participants so as to elicit more detailed responses or gather additional information from the respondents (Zhou \& Solan, 2009). In this research, interviews were undertaken in two parts; each participant was individually interviewed in the first part, face-to-face for approximately 30 minutes. In the second part of the interview, participants were asked to comment on two short videos.

\subsection{Data Analysis}

Questionnaire data was collected online via SurveyMonkey. The transcripts of all interviews were created in one file in order to show what each participant had actually said last. The researcher created extra appendices that simplified specific results obtained automatically. In analysing the data, the researcher used a constant 
comparison to generate insights that identified patterns of similarity or difference within the data. The research adopted open coding, which is the process of reducing data to a small set of themes that appear to describe the phenomenon of taboos under investigation (Leedy, 2010). This involved taking parts of expression from different participants and comparing participants' responses to reflect common themes. It was crucial to look carefully for words and phrases that indicated attributes and various kinds of causal or conditional relations. Two methods used in analysing the data were word co-occurrence and metacodings. A word co-occurrence approach is based on the observation that many words commonly occur with other words to form a particular idea (Gibbs, 2003). Metacoding examines the relationship among a priori themes to discover new themes and overarching meta themes. The study has adopted the Grounded Theory Approach that concentrates on the concept of generation of theories and models inductively from concentrates around the concept of generation of theories and models inductively from empirical data (Ellis, 1993).

When data is analysed by theme, it is called thematic analysis. This type of analysis is highly inductive; that is, themes emerge from the data and are not imposed upon it by the researcher (Dawson, 2009). Thematic analysis is a method for reporting, analysing and identifying patterns within data (Braun \& Clark, 2006). It has been introduced as a qualitative descriptive method that provides the necessary skills to researchers for conducting many other forms of qualitative analysis. They further recommend that qualitative researchers become more familiar with thematic analysis as a reliable and independent approach to analysis (Vaismoradi, Turunen \& Bondas, 2013). In order to analyse the data further, a computer software program, NVIVO was used for two reasons: it supports the storing and the manipulation of documents or texts and it supports the creation and the manipulation of codes known in NVIVO as nodes (Gibbs, 2003).

\section{Understanding LT Used by Lebanese Arabic Speakers of Different Generations}

\subsection{Use of Euphemism and Age Factor}

Euphemism was reported to be used by older participants in the literature, however, this study revealed that the age factor was not strongly related to euphemism when avoiding taboo words. Four participants out of 56 used euphemism as a strategy. Three participants (out of 42 young participants) and one old participant out of 14 old participants have used euphemism. As it can be seen only one older participant has used euphemisms in contrast to the other 13 older participants and this is a new trend in the study of sociolinguistics. The strategy found in their usage was to omit one or more letters of rather strong LT words, namely 'fu-k', ' $\mathrm{f}-\mathrm{-} \mathrm{k}$ dog', 'get f-' and ' $\mathrm{f}$ $\mathrm{u}-\mathrm{k}$ off'. They fell short of actually saying the taboo words. This shortened forms of the words can be considered as a possible form of euphemism as it serves the purpose of minimising the tone of the swearing words for the sake of purifying the speech. This strategy is similar to that of not spelling out the taboo words, especially if they are talking in front of children who are too young to sort it out. It is essential that speakers, regardless of their age, need to make an effort in a way of saving face at a time they are still conveying a message. Nevertheless, the speakers ought to shroud it in a language that is less offensive and this is the whole point of euphemism.

Alotabi (2015) was one of the researchers who concluded that older participants were more mindful of euphemism than young participants. Androutsopoulos and Georgakopolou (2008) also acknowledge the assumption that adolescent speech defies anything that is regulated and proper. In this study, however, older participants did not use as many euphemisms as would be expected and this result conforms to the unexpected trend of seeing younger participants using very similar expressions in order to avoid direct LT. The use of euphemism by younger participants is an exceptional one and these findings come only six years after the research of Miller and Caubet (2010), where it was shown that the speech of Arabic youth was a mixture of joking, interaction and teasing. A key question that can be asked is whether members of the younger generation are reforming their speech and becoming even more polite speech-wise than the older generation. These findings pose a real challenge for researchers to try to validate and point them to the necessity of conducting further extensive research.

One of the older participants in this study (OP14) stated that young people only use taboo words with people of their own age and avoid using them with people who are younger or older. This could be the reason why the younger participants in this study might have used euphemism because they were interviewed by an older interviewer. The results might have been different if the participants were interviewed by someone of the same age.

\subsection{Young Lebanese Speakers' Use of Arabic LT}

In order to compare the older people's use of LT with that of the younger people, this section explores briefly the young Lebanese speakers' use of Arabic verbal taboos. The analysis of interview data revealed that some factors 
may compel the young Lebanese speakers to use Arabic LT. These include adolescent swearing and peer pressure, social influences, and family influence. Adolescent swearing and peer pressure are two main reasons why the young Lebanese people use Arabic LT.

According to the questionnaire study, more than half of the participants (31 out of 56) consider that during their adolescence, Lebanese Arabic speakers test authority through the use of offensive words, while only a small minority disagree with this notion (9 out of 56). This is in line with the findings of Androutsopoulos and Georgakopolou (2008) who talk about the inevitability of youth defying authority. The majority of the participants (37 out of 56) agree that a speaker's age plays an important role in his or her evaluation of the extent of taboo violation. A slight majority of participants (35 out of 56) believe that the perception of LT depends largely on the interpersonal characteristics and attitudes of the individual rather than on other factors, while only a tiny minority think otherwise (6 out of 56). OP1 mentioned peer pressure as one of the factors that compels young people to use LT, as they want to act 'cool' and feel accepted.

Some participants have mentioned social influence as one of the reasons for either promoting or avoiding taboo words. YP11 lists oppression by society as one of the factors that compels some young Lebanese speakers to use Arabic LT. It can be said that young Lebanese speakers' feelings of discontent with society, as a result of oppression, might contribute to their rebellious behaviour and willingness to use strong LTs. On the other hand, YP10 considers new society may provide a ground where young Lebanese may refrain from using taboo words. YP10 compares the usage of LT words in both Lebanon and Australia by saying that young Lebanese speakers in Lebanon use more taboos than those living in Australia. According to this male participant, this could be an influence from the new environment where he believes that less taboo words are utilised. In his view, even recent arrivals display attitudes towards taboo that are not much different to those who have been in Australia for some time, which indicates how quickly some immigrants change their attitudes to match the new environment.

OP15 cites bad influences and kids' video games as some of the factors that force young speakers to use Arabic LT. Bushman and Anderson (2002) observe that people who have played a violent game behave more aggressively. It remains to be seen whether the aggressive nature of war in Lebanon might have influenced Lebanese speakers to use LT in their social interaction. It is more likely that these people will resort to using profane or obscene words. YP18 lists factors that might prompt young Lebanese speakers to use Arabic LT and these include the elderly, the environment and family. YP6 remarks that using LT allows her to express herself in her own culture. When people swear or use taboo words, they may be trying to convey a message about their personality. Jay (1999) notes that whether and how a child uses swear words depends on his or her personality, characteristics and social environment and that some personality factors, such as masculinity, are inextricably linked with the motivation to use curse words. Despite the fact that some Lebanese participants admitted to swearing, it does not mean that Lebanese culture approves of such behaviour. On the contrary, Lebanese culture outlaws any such offensive behaviour by its citizens who might be expressing their own personality but not necessarily the culture of their own society.

\section{Summary and Conclusion}

This paper examined how and why younger and older Arabic Lebanese speakers used LT, thus adding to our understanding of the complex and dynamic factors contributing to the sociolinguistic behaviours. The study has shown the unexpected results that the older participants aged 30 to 60 used less indirect taboo words in comparison to the younger participants aged 18 to 29. It has indicated that the majority of young participants refrained from using LT depending on who the interlocutors were, namely whether older people were present. The study has also revealed that only one out of 14 older participants used a euphemistic expression. This can be considered as one of the most unexpected findings. Although almost $50 \%$ of participants believe that older people use euphemistic expressions in the survey, this belief was not present in the interview outcomes. It is indicated that the Arabic Lebanese speakers' use of LT in Australia is context-dependent and complicated. It is certain that what is perceived has to be proved and supported through data-based research evidence.

The study has two limitations. First, the number of participants is not so large with 56 participants having completed the online questionnaire and 22 participants having attended the interview. Second, there was an uneven number of younger and older participants in study and the number of younger participants was predominantly larger than that of older ones due to limited participant availability and voluntary participation. Therefore, more comprehensive research is needed in order to confirm the result of this study by recruiting more and comparing the even number of younger and older participants using LT.

This study opens up the prospects of looking into the Australian Lebanese speakers' use of LT in different perspectives. For example, more participants from different ethnicities should be recruited in similar future studies 
in order to draw a comparison between ethnic community groups, to ascertain whether the results will be similar or different to the outcomes of this study. Other perspectives include data-driven investigation into the roles of gender, religions, education background of the Australian Lebanese speakers play in their use of LT. When these are put together, a comprehensive understanding of their use of Arabic linguistic and cultural taboos can be achieved.

\section{Acknowledgments}

This study is part of the full fulfilment of the Masters of Honours thesis completed by the first authors and supervised by the three supervisors as co-authors. We would like to thank Mrs Rola Khawaji for interviewing the female participants. Furthermore, we would like to thank the two anonymous reviewers for their helpful comments. Finally, we appreciate all the participants and other people for their time and assistance in the project.

\section{References}

Abdel-Jawad, H. R. S. (2000). A linguistic and sociopragmatic and cultural study of swearing in Arabic. Language, Culture and Curriculum, 13(2), 217-240. https://doi.org/10.1080/07908310008666600

Agyekum, K. (2002). Menstruation as a verbal taboo among the Akan of Ghana. Journal of Anthropological Research, 58(3), 367-387. https://doi.org/10.1086/jar.58.3.3631182

Al-Azzeh, I. (2010). The use of euphemisms by Jordanian speakers of Arabic.(MA. Thesis), Middle East University, Amman-Jordan. Retrieved July 9, 2016, from https://theses.ju.edu.jo/Original_Abstract/JUF0689 380/JUF0689380.pdf

Al-Khatib, M. A. (1995). A sociolinguistic view of linguistic taboo in Jordanian Arabic. Journal of Multilingual \& Multicultural Development, 16(6), 443-457.

Alotaibi, A. M. (2015). The awareness of euphemism by Kuwaiti speakers of Arabic. International Journal of Linguistics, 7(1), 69-81. https://doi.org/10.5296/ijl.v7i1.6428

Androutsopoulos, A., \& Georgakopolou, A. (2008). Youth, discourse, and interpersonal management. In G. Antos, E. Ventola, \& T. Weber (Eds.), Handbook of interpersonal communication (pp. 457-480). NY: De Gruyter Mouton.

Asad, T. (2008). Reflections on blasphemy and secular criticism. In H. de Vries (Ed.), Religion: Beyond a concept (pp. 580-609). New York: Fordham University Press.

Barbieri, F. (2008). Patterns of age-based linguistic variation in American English. Journal of Sociolinguistics, 12(1), 58-88. https://doi.org/10.1111/j.1467-9841.2008.00353.x

Blamire, E., Laturnus, R., \& Perez-Leon, A. (2013). Profanity across gender and age. Sojourners: Undergraduate Journal of Sociology, 5, 32-49.

Braun, V., \& Clarke, V. (2006). Using thematic analysis in psychology. Qualitative Research in Psychology, 3(2), 77-101. https://doi.org/10.1191/1478088706qp063oa

Burridge, K. (2010). Linguistic cleanliness is next to godliness: Taboo and purism. English Today, 26(2), 3-13. https://doi.org/10.1017/S0266078410000027

Bushman, B., \& Anderson, C. (2002). Violent video games and hostile expectations: A test of the general aggression model. Personality and Social Psychology Bulletin, 28(12), 1679-1686. https://doi.org/10.1080/ 08838151.2013 .787078

Chu, M.-P. (2009). Chinese cultural taboos that affect their language \& behavior choices. Asian Culture and History, 1(2), 122-139.

Dawes, J. (2008). Do data characteristics change according to the number of scale points used? An experiment using 5-point, 7-point and 10-point scales. International Journal of Market Research, 50(1), 61-77.

Dawson, C. (2009). Introduction to research methods: a practical guide for anyone undertaking a research project (4th ed.). Oxford: How To Books.

De Klerk, V. (1992). How taboo are taboo words for girls? Language in Society, 21(02), 277-289. https://doi.org/10.1017/S0047404500015293

Denscombe, M. (2014). The good research guide: for small-scale social research projects. UK: McGraw-Hill Education. 
Duda, B. (2011). Euphemisms and dysphemisms: In search of a boundary line. Circulo De Linguistica Aplicada a La Comunicacion, 45, 3-19. Retrieved August 12, 2016, from https://search.proquest.com/docview/ 925725647? accountid $=36155$

Eilola, T. M., \& Havelka, J. (2011). Behavioural and physiological responses to the emotional and taboo Stroop tasks in native and non-native speakers of English. The International Journal of Bilingualism, 15(3), 353-369. https://doi.org/10.1177/1367006910379263

Ellis, D. (1993). Modeling the information-seeking patterns of academic researchers: A grounded theory approach. The Library Quarterly, 63(4), 469-486. https://doi.org/10.1086/602622

Farghal, M. (1995). Euphemism in Arabic: A Gricean interpretation. Anthropological Linguistics, 37(3), 366-378.

Fershtman, C., Gneezy, U., \& Hoffman, M. (2011). Taboos and identity: Considering the unthinkable. American Economic Journal: Microeconomics, 3(2), 139-164. https://doi.org/10.1257/mic.3.2.139

Fitzpatrick, P. (1992). The mythology of modern law. London, United Kingdom: Routledge.

Fleming, L., \& Lempert, M. (2011). Introduction: Beyond bad words. Anthropological Quarterly, 84(1), 5-13.

Gibbs, G. R. (2003). Analysing qualitative data. London, UK: SAGE Publications Ltd.

Gobert, M. (2015). Taboo topics in the ESL/EFL classroom in the Gulf Region. In R. Raddawi (Ed.), Intercultural communication with Arabs: Studies in educational, professional and societal contexts (pp. 109-126). Singapore: Springer.

Halmari, H. (2011). Political correctness, euphemism, and language change: The case of 'people first'. Journal of Pragmatics, 43(3), 828-840.

Hart, H. L. A. (1977). Is law a system of rules. The philosophy of law. Retrieved April 20, 2016, from http://scholar.google.com.au/scholar?hl=en\&q=Hart+is+law+a+system + of + rules $+1977 \& b$ tnG $=\& a s \_s d t=1$ $\% 2$ C5\&as_sdtp=

Holmes, J. (1992). An introduction to sociolinguistics. London and New York: Longman.

Hummert, M. L., \& Mazloff, D. C. (2001). Older adults' responses to patronizing advice balancing politeness and identity in context. Journal of Language and Social Psychology, 20(1-2), 168-196.

Jay, T. (1999). Why we curse: A neuro-psycho-social theory of speech. Amsterdam/Philadelphi: John Benjamins Publishing Company.

Jay, T. (2009). The utility and ubiquity of taboo words. Perspectives on Psychological Science, 4(2), 153-161.

Johnson, S. (1995). English as a second $f^{*}$ cking Language: How to swear effectively, explained in detail with numerous examples taken from everyday life. New York: Macmillan.

Leedy, P. D. (2010). Practical research: Planning and design. (9th ed.): Upper Saddle River, NJ: Merrill.

Luffin, X. (2002). Language taboos in Kinubi: A comparison with Sudanese and Swahili cultures. Africa, 57(3), 356-367.

Maqdum, M. (2011). Almahzourat Al-loukhaweyi (The linguistic taboos). Retrieved September 13, 2016, from https://mufatismaqdum.wordpress.com/2011/12/21/\%D8\%A7\%D9\%84\%D9\%85\%D8\%AD\%D8\%B8\%D9 \%88\%D8\%B1\%D8\%A7\%D8\%AA-\%D8\%A7\%D9\%84\%D9\%84\%D8\%BA\%D9\%88\%D9\%8A\%D8\%A9/

Miller, C., \& Caubet, D. (2010). Arabic sociolinguistics in the Middle East and North Africa (MENA). In M. Ball (Ed.), The Routledge handbook of sociolinguistics around the world (pp.238-256). NY: Routledge.

Murphy, B. (2009). 'She's a fucking ticket': the pragmatics of fuck in Irish English: An age and gender perspective. Corpora, 4(1), 85-106. https://doi.org/10.3366/E1749503209000239

Qanbar, N. (2011). A sociolinguistic study of the linguistic taboos in the Yemeni society. The Modern Journal of Applied Linguistics, 3(2), 86-104.

Ritt-Benmimoun, V., \& Procházka, S. (2011). Female issues in Arabic dialects: Words and expressions related to the female body and reproduction. Estudios de Dialectología Norteafricana y Andalusi (EDNA) (13), 31-92.

Sabri, O. (2012). Preliminary investigation of the communication effects of "taboo" themes in advertising. European Journal of Marketing, 46(1/2), 215-236.

Stenstrom, A.-B. (2006). Taboo words in teenage talk: London and Madrid girls conversations compared. Spanish in Context, 3(1), 115-138. 
Sue, V. M., \& Ritter, L. A. (2007). Conducting online surveys. Thousand Oaks, CA: Sage.

Thanjitt, S. (1998). Verbal taboo in Thai. Bangkok: National Institute of Development Administration.

Thelwall, M. (2008). Fk yea I swear: cursing and gender in MySpace. Corpora, 3(1), 83-107.

Triandis, H. C. (2001). Individualism-collectivism and personality. Journal of Personality, 69(6), 907-924. https://doi.org/10.1111/1467-6494.696169

Vaismoradi, M., Turunen, H., \& Bondas, T. (2013). Content analysis and thematic analysis: Implications for conducting a qualitative descriptive study. Nursing \& Health Sciences, 3(15), 398-405. https://doi.org/10. $1111 /$ nhs. 12048

Zhou, S., \& Sloan, W. D. (2009). Research methods in communication. Northport, AL: Vision Press.

Ziman, H. (2008). Sex taboo in literary translation in China: A study of the two Chinese versions of The Color Purple. Babel, 54(1), 69-85.

Zuskin, R. D. (1993). Assessing L2 sociolinguistic competence: In search of support from pragmatic theories. Retrieved June 8, 2016, from http://files.eric.ed.gov/fulltext/ED396556.pdf

\section{Copyrights}

Copyright for this article is retained by the author(s), with first publication rights granted to the journal.

This is an open-access article distributed under the terms and conditions of the Creative Commons Attribution license (http://creativecommons.org/licenses/by/4.0/). 